\title{
McTv
}

\section{Bidrag til en forståelse af tv-formaternes globale popularitet}

\author{
Af Silvio Waisbord
}

Globaliseringen har knyttet verdens tv-industrier tettere sammen. Strukturelle og institutionelle forbindelser mellem tv-systemer og tv-industrier har skabt en tv-branche, der $i$ stigende grad styres af de samme praksisser og mål. Denne dynamik afspejles $i$ tv-formaternes popularitet. På overfladen bidrager den globale udbredelse af tv-formater dog ikke kun til en global integration af industriens økonomi men også til en standardisering af programmernes indhold. Få store medieselskaber salger idéer på et internationalt marked, således at seerne tilsyneladende ser nationale variationer af de samme programmer. På et dybere niveau viser salget af formater dog, at to stadig er knyttet til lokale og nationale kulturer. Med eksempler fra Latinamerika argumenterer denne artikel for det synspunkt, at to på én gang er globalt og nationalt formet både af de globaliserede medieøkonomier og af de lokale og nationale kulturer.

I 1980erne virkede det som om tv's globale programflade var på vej til at blive et "væg-til-væg Dallas". Den grundlæggende forandring, der på dette tidspunkt skete med strukturen i europæisk tv, resulterede i en mangedobling i importen af amerikanske programmer, og denne situation skabte bekymring for nationalt tv og frygt for amerikansk kulturimperialisme. På det seneste virker det som om, vi har fået et væg-til-væg format - som dog ikke entydigt er af amerikansk oprindelse. Verden over fyldes tv-fladerne nemlig med nationale variationer af programmer designet af selskaber fra mange forskellige lande.

Formater er program-idéer, der er adapteret og produceret til bestemte nationale publikummer. Handlen med formater er ikke ny. I årtier er der blevet produceret og solgt formater af quiz- og fiktionsprogrammer på de internationale markeder (Moran 1998). Men som fagpressen for nylig har beskrevet det, har "format tv" taget industrien med storm. På de seneste tv-messer har tv-selskaberne udbredt sig om formaternes kvaliteter, og paneldeltagere fra industrien har diskuteret forskellen mellem reality-formater og programmer med traditionelle drejebøger.
Formaternes popularitet er mere end en trend i en industri, der til stadighed hungrer efter hit-programmer og ivrigt efterligner dem. Det afslører to udviklinger inden for tidens tv: Globaliseringen af tv-branchens forretningsmodel og de internationale og nationale selskabers forsøg på at håndtere de nationale kulturers levedygtighed. Analysen af disse udviklingstræk kan tydeliggøre, hvordan økonomi og kultur er forbundet i forbindelse med medieøkonomiernes globalisering.

I den første del af denne artikel argumenterer jeg for, at når globaliseringen forstås som mediepolitik og teknologisk udvikling, så kan man iagttage en større kontakt mellem verdens tv-industrier skabt af strukturelle og institutionelle forbindelser mellem tv-systemer og tv-industrier. Resultatet er en branche, der hænger sammen på mange niveauer og styres af de samme praksisser og mål. I artiklens anden del undersøger jeg, hvad formaternes popularitet fortæller os om de nationale kulturer i en global verden. På overfladen bidrager den globale udbredelse af tv-formater ikke kun til en integration af industriens økonomi men også til en standardisering af programmernes indhold. Finder man et bedre eksempel på kulturel ensretning end format-tv? Få store medieselskaber kan 
sælge de samme idéer på et internationalt marked, således at seerne tilsyneladende ser nationale variationer af de samme programmer. På et dybere niveau viser format-salget dog, at tv stadig er knyttet til lokale og nationale kulturer. Med eksempler fra Latinamerika argumenterer denne artikel for det synspunkt, at tv på én gang er globalt og nationalt, formet af både de globaliserede medieøkonomier og de lokale og nationale kulturer.

\section{Privatisering og efterspørgsel efter format-programmer}

1980ernes og 1990ernes massive forandringer i tv-systemernes struktur har forbundet tv-systemer, der indtil da fungerede i relativ isolation. Tv blev opfattet som en national beskyttet industri, og den globale handel med tv-programmer blev mødt af lovgivningsmæssige forhindringer. I de seneste årtier har privatisering, liberalisering og deregulering af luftbølgerne fjernet sådanne begrænsninger og åbnet tv-systemerne for kapital- og programstrømme. Dette har resulteret i, at systemerne er blevet mere ens og domineres af principper om privat ejerskab og profit.

Før den seneste bølge i globaliseringen havde de fleste tv-industrier et begrænset antal sendetimer, de skulle udfylde. Fremvæksten af flerkanalsystemernes liberaliserede miljø åbnede mulighed for, at storproducenter kunne nyde godt af en stigende efterspørgsel skabt af en eksplosion i antallet af sendetimer. Med velassorterede videoteker, veletablerede distributionsnetværk og en overlegen markedsføringsmaskine virkede det som om Hollywood-selskaberne var forprogrammeret til at profitere på disse forandringer. Det faktum, at de fleste lande skiftede til en "amerikansk" tv-model, var en klokkeklar fordel for den industri, der havde opfundet den.

Da kommercielt tv's principper blev standardiseret og industrierne modnedes, viste det sig dog alligevel, at andre landes industrier formåede at producere og eksportere programmer, specielt hvis de henvendte sig til seernicher. Det, der var godt for Hollywood, kunne under de rette betingelser også være godt for produktionsselskaber fra andre lande, så længe de beherskede det kommercielle tv's præmisser. Således har flere dusin tv-selskaber med base i Vesteuropa, Australien og New Zealand fået fodfæste på det globale tv-marked. Dette kan anskueliggøres af den globale handel med tv-formater. Mange vesteuropæiske selskaber har rettighederne til tidens store hit-formater. Ifølge fagpressen er Europa førende indenfor reality-tv (Fry 2000). Den succes, som engelske Calador og Pearson, hollandske Endemol og svenske Strix har haft, viser, at format-produktionen ikke længere er begrænset til Hollywood.

Pearson praler af at være "Englands eneste globale tv-producent med over 160 programmer i produktion i 35 lande over hele verden". Hittet "Who Wants to Be a Millionaire" er solgt til 79 lande (Schneider 2000). BBC har solgt "The Weakest Link" til 38 lande. Det Telefonica-ejede Endemol har tæppebombet verden med "Big Brother" og andre reality-programmer. Strix har skabt det uhyre populære "Robinson Ekspeditionen" (kendt som Survivor) og "Baren". Disse selskabers succes er blevet set som udtryk for vigtige forandringer i de europæiske medier og den skarpere konkurrence for Hollywood (Andrews 2000, Carter 2000). De har opnået det, som kun en håndfuld engelske produktioner havde opnået inden, nemlig at sælge formater på det næsten uigennemtrængelige amerikanske marked (se O'Regan 2000). Udviklingen har fået visse kommentatorer til at tale om et tovejs transatlantisk flow (Guider 2000), mens andre decideret hævder, at den amerikanske indflydelse bliver mindre (Jensen 2000), og at " $t v$ imperialismen går baglæns" (Moyes 2000).

Selvom det er sandt, at nogle europæiske produktionsselskaber har nydt godt af de forandringer globaliseringen har skabt i de seneste årtier, er ovenstående konklusioner noget forhastede og overser de enorme uligheder, der stadig eksisterer på det globale marked for film og tv. At hævde at Hollywoods indflydelse bliver mindre eller møder modstand baseret på en håndfuld ikke-amerikanske selskabers succes er absurd, når man tager i betragtning, at Hollywood har udvidet sin verdensomspændende tilstedeværelse.

Også en håndfuld ikke-europæiske selskaber er blevet vigtige producenter og eksportører af tv-programmer. Antallet af nye udbydere er vokset støt ved internationale handelsmesser som f.eks. National Association of Television Program Executives (NATPE) og Marche International de Films et de Programmes pour la TV, la Video le Cable et les Satellites (MIPCOM). Japanske firmaer, hvis traditionelle eksportvarer primært omfatter tegneserier og dokumentarfilm, sælger nu drama og "gameshow"-formater. Producenter fra Hong 
Kong, Ægypten og Indien konsoliderer deres tilstedeværelse i deres respektive sprogområder og på de tosprogede markeder (Sinclair, Jacka og Cunningham 1996). Mexikanske og brasilianske medievirksomheder finder nye muligheder i globalt tv, primært gennem salget af telenovellaer (Sinclair 1999, Straubhaar 1991). I de senere år har visse Latinamerikanske producenter også eksporteret formater til USA og mange europæiske lande.

Dog kan fremvæksten og konsolideringen af tv-eksportører fra forskellige regioner næppe betragtes som bevis for, at Hollywoods dominerende position på det globale tv-marked er blevet udfordret, endsige at uligheden i det globale flow af tv og information er blevet udlignet (Biltereyst og Meers 2000; Golding 1998). Uden at forklejne den succes visse producenter fra den tredje verden har fået, er den vestlige dominans i salget af programmer (og med hensyn til industriens struktur) stadig indiskutabel. Selvom mængden af globale eksportører er vokset udover de traditionelle Hollywood studier i takt med at industrierne er blevet modne, har firmaer fra store og rige lande større chancer for at blive globale eksportører.

De ti største udstillere ved den seneste MIPCOMmesse var firmaer baseret i USA, Vesteuropa og Japan. I slutningen af 1980erne stod USA for $71 \%$ af den totale trafik med tv-programmer. Det er estimeret, at procentdelen af amerikanske programmer er faldet til $60 \%$ i takt med at andre tv- industrier er modnet, og indenlandske programmer opnår de højeste seertal. Lokalpræference for indenlandske eller regionale programmer betyder ikke nødvendigvis, at Hollywoods formuer svinder ind. Beregninger viser, at de seks store Hollywoodstudier indtjente mellem $\$ 5,4$ og $\$ 5,5$ mia. i 2001 - mere end resten af verden til sammen (Pursell 2001). Selvom markedet for programeksport er blevet mere mangfoldigt, hvad angår antallet af producenter, og mere sammensat, hvad angår måden programmer bevæger sig over landegrænserne på, er magtforholdet næppe udlignet.

\section{Forklaringen på tv-formaternes popularitet}

Formaternes popularitet er resultatet af mange udviklinger. For det første er det et uintenderet biprodukt af protektionistisk lovgivning på tv-området. I visse lande, såsom Indonesien, er brugen af undertekster forbudt, og programmerne sendes på engelsk eller på lokale sprog. Sådanne protektionistiske restriktioner fik stationerne til at købe udenlandske manuskripter og producere dem nationalt uden undertekster. Kvote-politik favoriserer også formater frem for udenlandske programmer. Af hensyn til national kultur og nationalt tv, har mange europæiske lande kvoter som primært har til formål at imødegå importen af Hollywoodprogrammer (Grantham 2000; Tunstall og Machin 1999). Programkvoter har smuthuller, som tillader udenlandske ideer (men ikke udenlandske programmer), bare de er produceret i hjemlandet. Formatprogrammer er således en del af en forretningsstrategi, hvis formål er at omgå lokale programkvoter. Når stationerne sender hjemlige versioner af udenlandske programmer, er disse programmer med til at opfylde kvotekravene. Så ved at sælge formater kan Hollywoodstudierne og Latinamerikanske producenter for eksempel komme ind på beskyttede europæiske markeder ved at sælge manuskripter og formater og ved at co-producere med indenlandske firmaer.

Udover protektionistisk lovgivning er tv-fomaternes succes eksploderet på det seneste på grund af reality-programmer som "Survivor" og "Big Brother", specielt i USA. Som andre kulturindustrier er tv-industrien domineret af "ingen ved" princippet (Graves 2000, Gitlin 1983) med konstant ebbe og flod i programtrends. Fordi der ikke er nogen sikkerhed ift. et bestemt programs eller bestemte genrers succes, så skaber hit-programmer uundgåeligt trends. Kopier, imitationer og hoppen med på vognen af, hvad der for tiden synes at virke, har kendetegnet tv-industrien siden dens barndom, og er uden tvivl blevet mere udbredt på det seneste i takt med, at konglomeratiseringen har øget profit-kravet.

Før den seneste fase i globaliseringen holdt trends sig overvejende indenfor nationale grænser. Da tv-systemerne var organiseret efter andre principper, var det ikke så let for stationernes ledelse at adaptere succesrige trends fra USA eller kommercielt europæisk tv. Det, der virkede på kommercielt tv, virkede ikke nødvendigvis på public service eller på statskontrollerede kanaler - og omvendt. Strukturelle reguleringer og institutionelle forventninger begrænsede programvalgene. Før programtrends kunne blive globale, måtte tv-systemerne følge de samme principper. Da først denne begrænsning var fjernet og kommercielle principper dominerede, kunne det, der virkede i det ene system, 
bruges andre steder. Ved at standardisere tv-strukturen opmuntrede globaliseringen tendensen til imitation og den modstand mod fornyelse, der kendetegner kommercielt tv.

Globaliseringen satte også fart i integrationen af tv-systemerne via branchenetværk og professionelle netværk. Mediekorporationernes globale tilstedeværelse lagde grunden for programmernes standardisering. Internationale virksomhedsnetværk cirkulerer information om, hvad der virker og ikke virker. Virksomhedsledere har ikke nødvendigvis kendskab til program-trends og seerpræferencer $\mathrm{i}$ alle lande, men de er sandsynligvis opdateret om tidens trends i USA og bringer de erfaringer, som de i de fleste tilfælde har gjort sig $i$ vestens tv-industrier, rundt i hele verden. Selvom de har fornemmelse for den lokale smag og overlader mange beslutninger til deres lokale afdelinger, som kender de lokale seere, er deres kommercielle og æstetiske dømmekraft sandsynligvis informeret af vestens trends og produktionsværdier. Sådanne erfaringer udgør beslutningsgrundlaget for programideer. Således har lokale programchefer større sandsynlighed for at få tilslutning til deres ideer, hvis de benytter sig af formater, som deres chefer $\mathrm{i}$ Miami, London eller Los Angeles kender, eller hvis de vælger programmer, der har æstetiske værdier og produktionsværdier, som cheferne kender. Den voksende homogenisering af den faglige sensibilitet hos tv-selskabernes chefer, forankret i Hollywoods verdensbillede, er et vigtigt aspekt af "den ny internationale fordeling af kulturarbejdet" (Miller et al 2001), som fortjener et studie. Globaliseringen har skabt en kosmopolitisk klasse af tv-fagfolk, der fra New York til New Delhi i stigende grad deler de samme begreber om og holdninger til, hvad der virker, og hvad der ikke gør i kommercielt tv. Endvidere har globaliseringen af tv-branchen introduceret og forbedret de uformelle netværk, der udbreder information om branchen. Tv-selskabernes chefer er i højere grad klar over, hvad der hitter, samt hvilke trends og præferencer der dominerer - særlig i USA. Hollywood er givet ikke længere den altdominerende leverandør af tv-programmer på verdensplan, som tilfældet var i tidligere årtier. Amerikansk tv er dog stadig centrum for den globale tv-industri. Tv-stationer verden over holder et godt øje med, hvad der virker på amerikansk tv.

Tv-messer, fælles fagblade og jævnlig elektronisk kontakt resulterer i mange personlige kontakter og fællesreferencer hvilket igen danner grund for et udbredt kendskab til globale tendenser. Antallet af deltagere ved tv-messer og -konferencer er vokset voldsomt det seneste årti. Ved disse møder skabes en fælles tankegang blandt selskabernes chefer. MIPCOMs motto lyder: "MIPCOM speaks the unifying dialogue of the industry: Business". Antallet af fagblade med international distribution og læserskare er også steget. Visse ugeblade og månedsblade har regelmæssigt sektioner om internationalt tv og om industriens tilstand i regioner og lande rundt om i verden. Endelig har adgangen til kommunikationsteknologier såsom kabel, satellit og internet gjort adgangen til information om andre landes programmer lettere. I takt med at disse interpersonelle og teknologiske netværk er blevet skabt, er det blevet et fagligt imperativ for tv-selskabernes ledere at kende til de globale tendenser.

I den forstand reflekterer tv-formaternes popularitet globaliseringen af tv-trends. De tilbyder en vis forudsigelighed, hvad angår kommerciel succes. I en tid hvor sådanne dynamikker er næsten universelle, tilfredsstiller formaterne det dobbelte behov for billige programmer og mange seere. Kommercielt tv efterspørger konstant nye og billige programmer, som kan tiltrække seere, der kan sælges til annoncører. Nogle af de mest populære formater såsom "gameshows" og realityprogrammer kræver normalt mindre investeringer end fiktion, da de ikke involverer skuespillere eller kendte manuskriptforfattere. Gennemsnitsprisen for ABCs "Who wants to be a Millionaire" er $\$ 750.000$ sammenlignet med $\$ 1,2$ mill for ABCs "The Practice"; NBCs "Twenty-one" koster ikke mere end $\$ 700.000$ contra $\$ 1,4$ mill. for en episode af "Law and Order"; et afsnit af "Survivor" koster $\$ 200.000$ tre gange mindre end de $\$ 600.000$ et afsnit af King of Queens koster (Weinraub 2000). I England estimeres det, at et afsnit af et populært quiz-show koster $£ 200.000$ sammenlignet med $£ 1$ million for en dramaproduktion (Hughes 2001). Ikke overraskende har skuespilleres, forfatteres og teknisk personales fagforeninger fra Argentina til USA modarbejdet format-tv, da de mener, det truer deres jobs.

Ud over lavere omkostninger så tilbyder importerede formater en vis grad af forudsigelighed baseret på deres tidligere præstationer i andre lande. Det konstante og stigende krav om profit betyder, at der er meget lidt, om nogen, tid til fornyelse eller til at forsøge sig med nye ideer. Afprøvede idéer 
kan mindske risikoen ved en investering, og formater er den ultimative risikominimerende programstrategi. Ejerne af formater tilbyder omfattende erfaringer som bl.a. indbefatter en oversigt over, hvordan formatet har præsteret i forskellige lande, hvad der har virket, og hvad der ikke har virket og informationer om nationale variationer. Producenter af gameshows har fx en mængde statistik om de forskellige spil og detaljeret information om produktioner, som ofte trækker på hundredvis af programtimer på flere kontinenter.

Visse formatprogrammer (særligt reality-shows) er også attraktive for tv-selskaber, fordi de giver mulighed for at skabe stor trafik på deres web-sider, som rummer interaktive spil, quizzer og oplysninger om deltagerne. Formatejerne har testet deres varer over hele verden og lægger vægt på, at deres produktioner kan integrere tv og internet og dermed øge afkastet. Desuden kan tv-stationerne tjene ekstra penge på at udgive fanblade og magasiner om programmerne og de berømtheder de skaber.

\section{Tv-formater og nationale kulturer}

Det ville være reduktivt kun at forsøge at forstå formaternes popularitet i lyset af forandringer i tv-systemernes struktur. De reflekterer også mødet mellem økonomi og kultur på det globale marked. Et internationalt flow af standardiserede, delokaliserede formater viser, at seerne er præget af en lokal og national bevidsthed. Dette virker måske ironisk, hvis vi antager, at globaliseringen uundgåeligt vil udslette kulturel mangfoldighed og skabe ensretning. Den modsætning, der ofte knyttes til globaliseringen - som skaber af hhv. en kommerciel samlebåndskultur eller som drivkraft for kulturblanding og -modstand - er falsk. Globale medier og det nationale er ikke antiteser men er faktisk integreret på en ganske kompleks måde.

Tv-formaternes popularitet skal findes i spændingsfeltet mellem de globale og lokale dynamikker, der præger tv's kulturelle økonomi. Tidens tv er en Janus-hovedet industri, som i profittens navn varegør virkelige og forestillede nationer i samme nu, som de er åbne overfor det globale flow af ideer og penge. Den globale cirkulation af formater er svaret på programstrategier, der skal bygge bro over transnationale økonomiske interesser og et nationalt tilhørsforhold. Sådanne strategier hverken følger patriotiske værdier eller er udtryk for, at tv pligtopfyldende respekterer mangfoldigheden af nationale kulturer. De er snarere resultatet af ønsket om profitmaksimering i en situation, hvor "det nationale" stadig er en hjørnesten i den kulturelle identitet. Som en konsekvens af dette, genskaber $o g$ forstærker programlægningen nationale følelser. Formaterne afspejler den økonomiske globalisering af tv-industrien og styrken af de nationale kulturer i en netværks-verden. De gør det muligt at tilpasse succesrige programmer til nationale kulturer. Til forskel fra importerede programmer, giver de tvstationerne en troværdig og formbar løsning, når der skal produceres potentielle hit-programmer. De fleste udenlandske programmer løber ind i kulturelle barrierer og har derfor mindre chance for at blive store succeser. De er billigere end egne produktioner og en billig strategi til at fylde programfladen ud, men de bliver næppe seer-magneter.

Sammenlignet med importerede programmer tematiseres kulturproblemet anderledes i formaterne. Formater bærer betydninger med sig, som ikke nødvendigvis er knyttet til bestemte nationale kulturer. Formater er kulturelt specifikke men nationalt neutrale. Formaternes DNA er rodfæstet i kulturelle værdier, som overskrider det nationale. Tekstlæsninger af populære formater som fx game shows peger på, at de er fortalere for forbrugskulturen (Fiske 1990; Otnes 1996). "Reality shows" som "Survivor" kan læses som den globale projektion af kapitalisme, nøgen individualisme og konkurrence. Til gengæld er format shows mindre tilbøjelige til at have specifikke referencer til det lokale og nationale, netop fordi de er skabt til at kunne rejse over grænser. Formater udvisker bevidst det nationale. Kan man sige, at "Big Brother" er et umiskendeligt hollandsk show? Er der noget, der gør "Baren" svensk eller "Taxi Orange" østrigsk? På hvilken måde repræsenterer "Waku Waku" den japanske nationalidentitet? Hvad er det engelske ved "Who wants to be a millionaire?" Fordi formater eksplicit tømmer tegnene for det nationale, kan de nationaliseres - dvs. tilpasses den hjemlige kultur. For kommercielt tv er dette fordelen ved tv-formater frem for importerede programmer. Fordi formater udgør fleksible formler, kan spor af nationalt tilhør tones ned og slettes. Resultatet er et pasteuriseret, transnationalt produkt afkoblet fra nationale kulturer. Formater afslører i virkeligheden "glokaliseringens" dynamikker (Robertson 1992) i jagten på profit: tilpasningen af programformler til det hjemlige publikums smag. 
Hollywood-fyldte programflader over hele verden kunne tyde på, at seerne foretrækker amerikanske programmer, og at Hollywood kan drage "konkurrencemæssig fordel af sine programmers narrative transparens" (Olson 1999). Hverken publikums præferencer eller Hollywoodfortællingens angivelige tekstuelle universalitet er imidlertid forklaringen på Hollywoods globale tilstedeværelse. Sådanne argumenter underspiller eller ignorerer den globale kulturelle økonomis struktur og tv-industriens institutionelle dynamik, der gør bestemte valg oplagte. Seernes valg følger industriens dynamik og beslutninger. At hævde, at programfladerne præcist afspejler seernes smag, er udtryk for en forestilling om, at forbrugerne suverænt afgør vareudbuddet, og hermed ignoreres mange af de kræfter og beslutninger, der former programfladerne. Når tv organiseres efter kommercielle principper, afhænger programfladernes sammensætning af nationale og udenlandske programmer af profitkalkulationer og producenternes forretningssans, når de skal sælge deres varer på forskellige markeder.

Snarere end at forstå programfladernes indhold som en konsekvens af seernes smag, må de forstås som et resultat af omkostninger og branchepraksis. Beslutninger tages på grundlag af selskabernes tro på, hvorvidt en substantiel investering er profitabel. Sådanne beregninger afhænger af det forhold, at ikke alle tv-industrier tilbyder de samme betingelser for national produktion. Når de økonomiske betingelser er gunstige (stordrift fordele, reklameindtægter, stort seergrundlag), er der større sandsynlighed for at tv-selskaberne producerer deres egne programmer, selvom omkostningerne er større end ved at købe udenlandske shows. Men selv under disse betingelser kan tv-selskaberne vælge at producere billige programtyper (talkshows, nyheder, variety-shows, game shows) frem for dyre genrer (fiktion, dokumentar), særligt i små lande.

Selv når markedet tillader en vis lokal produktion, foretrækker man at fylde programfladerne med udenlandske programmer, fordi det er markant billigere. I det seneste årti har seertal bekræftet, at når de får valget, så foretrækker seerne hjemligt og regionalt tv frem for udenlandsk (Hoskins, McFayden, og Finn 1997; Langdale 1997; Waisbord 2000a, Waterman og Rogers 1994). Dette er dog ikke en indikation af mulighedsbetingelserne for at producere tv der afspejler lokale erfaringer. Publikum foretrækker måske nok lokalt indhold, alligevel kan tv-selskaberne vælge ikke at producere det. Kun under særlige økonomiske og industrielle omstændigheder kan lokale programmer true Hollywoodprogrammer i prime time, og Hollywood-produktioner bruges desuden som fyld i yderperioder, når seertallene og reklameindtægterne er mindre. Det er ikke alle tv-industrier, der har kapacitet til at producere så mange timer, at de kan efterkomme efterspørgslen.

Set i lyset af tv-industriernes forskellige muligheder for produktion, er seernes "lokalisme" en vigtig faktor, særlig når markederne er store og velhavende. Derfor vælger mange kabel- og satellitnetværk at dele deres signaler langs kulturelle skel ved at tilbyde regionale programmer. MTV, ESPN og andre kabel netværk har indset, at programmer på de lokale sprog, som præsenterer lokale talenter og tager højde for lokale præferencer, har bedre indtjening end et-sprogede udsendelser - kun for "amerikanere" (Hils 1998; Koranteng 1999). Disse stationers programflader rummer i stigende grad lokalt og regionalt produceret stof. Det er ikke let at sige præcis, hvad det er seerne foretrækker ved lokale programmer. Industrien giver for det meste efterrationaliserede ad hoc forklaringer på, hvorfor bestemte programmer er blevet populære. Forklaringerne garanterer ikke nødvendigvis, at programmer med lignende kendetegn vil kunne opnå samme seertal. Generelt antages det, at seerne vælger programmer, som afspejler deres egen kultur. For at belyse denne antagelse, har jeg analyseret forholdet mellem formater, fortællinger og sprog på det latinamerikanske tv-marked.

\section{Formater og fortællinger}

Det synes at være en almindelig antagelse $\mathrm{i}$ industrien, at tv-seerne kan lide at møde velkendte temaer, steder og figurer på tv. Humor og drama er favoritter, fordi de ofte er rodfæstet i lokale og nationale kulturer, hvilket også forklarer appellen ved nyheder og sportsreportager. Nyhedsreportager forankrer fællesskabsfølelsen ved at skabe en fælles viden om, hvad der er på samfundets dagsorden. Sportsudsendelser giver mulighed for at gennemspille og udtrykke lokale og nationale følelser. Og samtidig giver tv-sporten den nationale identitet vigtige kommercielle og ideologiske funktioner (Whannel 1993).

På trods af at universelle historier og fremmede steder kan være fascinerende, foretrækker seerne altså fortællinger, der indeholder kendte elementer. 
Derfor foretrækker seerne programmer fra lande i "kulturel nærhed" (Straubhaar 1991). Alligevel kan seerne føle sig fremmede overfor noget så nært som co-produktioner mellem lande, der har samme sprog. I Latinamerika har man forsøgt sig med telenovellaer, der havde skuespillere fra forskellige lande og historier, der vekslede mellem mange lande i regionen. De har floppet fælt. Ifølge de ledende tv-folk, som jeg har interviewet, floppede de, fordi de var et kulturelt sammensurium, en "latiner-budding" som uden succes prøvede at udtrykke en fælles regional identitet. Resultat var en samling spredte referencer til nationale kulturer, som i sidste ende manglede kulturelt særkende. End ikke populære nationale tv-stjerner gav højere seertal i deres hjemlande.

Seernes præference for hjemligt indhold skaber et dilemma for tv-selskaberne: Indhold som er stærkt indlejret $\mathrm{i}$ lokale og nationale kulturer har en større chance for succes men har mindre chance for at finde interesserede købere og begejstrede seere i udlandet. Fordi salg til udlandet er af sekundær betydning for de fleste latinamerikanske selskaber, afhænger telenovellaernes succes primært af det hjemlige publikum. Desuden forholder det sig sådan, at telenovellaerne har deres største publikum i byerne (hvor produktionsselskaberne også ofte er placeret), hvilket betyder, at de ofte afspejler de store byers lokale kultur. I Argentina står Buenos-Airos og omegn for 78\% af den samlede mediereklame og $60 \%$ af alle hjem med tv. Det kan således ikke undre, at seerne i det indre Argentina opfatter de fleste produktioner som "porteñas" (betegnelsen for beboerne og kulturen i Buenos-Airos).

Fordi hjemlige markeder og særligt storbyerne er så centrale for tv-økonomien, har producenterne en tendens til at inkludere lokale historier, humor og karakterer i deres programmer, selv om det skader salgsmulighederne til udlandet. Derfor har produktioner, der i branchesproget er "for lokale", som $\mathrm{fx}$ periode-telenovellaer eller programmer, der forudsætter viden om lokale politiske forhold, sværere ved at finde internationale markeder end programmer, der er løsrevet fra det lokale.

I Latinamerika er der en lang tradition for telenovellaer, der beskriver klassiske kærlighedshistorier og familiekonflikter i lyset af historiske og politiske kampe. Flere forskere har peget på, at de har fået deres succes i hjemlandet, netop fordi de har formået at give seerne mulighed for at opleve sig selv som en del af et kulturelt fællesskab (Allen 1995; Martin-Barbero 1993). Problemet er, at deres eksport-potentiale er begrænset. Bliver de solgt, er det ofte pga. deres lave pris. Hollywood-produktionernes relativt højere pris har været en fordel for de latinamerikanske produktioner i Østeuropa og Asien i 1980erne og 1990erne.

I modsætning til de nationale produktioner så har telenovellaer, der fortæller universelle kærlighedshistorier ( $\mathrm{fx}$ Askepot-agtige plots) uden lokale referencer og med kendte stjerner, færre problemer med at krydse kulturelle grænser. Det bedste eksempel er Mexicos Televisa-producerede telenovellaer. Deres bemærkelsesværdige succes i lande som Rusland og Filippinerne er blevet forklaret med det forhold, at nationale referencer er stort set fraværende - bortset fra skuespillernes udstråling.

Sammenlignet med de brasilianske "periode"- og samtids-telenovellaer (Trinta 1998) og TV Aztecas telenovellaer, som tager udgangspunkt i en politiske sager, er Televisas historier ofte universelle.

I modsætning til de importerede programmer, som er nedsunket i bestemte nationale kulturer, er formater åbne tekster, der kan tilpasses. Inden for de rammer, der dikteres af format-ejeren, kan lokale produktioner sætte lokale fortællemåder, historier, humor, begivenheder og karakterer ind i den formel, de køber. Fordi formater grundlæggende er åbne, kan de ikke udelukkende opfattes som bærere af vestlig kultur. Albert Moran (1998) hævder fx, at formater skal forstås som forhandlingsrum for mødet mellem hjemlig og fremmed kultur snarere end som trojanske heste for vestlig kultur.

Formater hverken fastholder et statisk syn på national kultur eller udgør rene formidlere af udefrakommende værdier. De er tekster, hvori forskellige forståelser af national kultur projiceres $\mathrm{og}$ omdefineres i lyset af de importerede formler. Man kan ikke konkludere, at nationale kulturer er "ofre for" tv-formater, for så ignorerer man formaternes fleksibilitet og seernes aktive rolle $\mathrm{i}$ tv-forbruget (se også Skovmand 1992).

Format-tv organiserer nationale oplevelser. Selv reality-programmer, der i modsætning til periodeog samtidsfiktion ikke udelukkende er skabt til at udtrykke nationale fortællinger, giver rum for artikulationen af det nationale. Særligt i tider, hvor nationalt tv har meget få grunde til at producere fiktion og foretrækker at vise billige programmer, skal man ikke ignorere det forhold, at gameshows, variety-shows eller reality-shows giver mulighed for, 
at publikum kan genkende sig selv som medlemmer af nationale fællesskaber. Spørgsmålet om, hvordan det nationale udtrykkes og genskabes i disse genrer, har dog ikke fået opmærksomhed nok. De fleste studier har prioriteret tekstanalyser af "high brow" programmer (dramaer, dokumentarprogrammer), som bevidst afgrænser kulturelle grænser gennem historiske fortællinger og ved at trække på en kollektiv erindring. Bortset fra bestemte genrers tekstlige kendetegn er tv flettet sammen med det nationale på mange forskellige måder. Det er ikke kun sådan, at det nationale kommer til udtryk på bestemte tidspunkter, når programmer appellerer til nationalistiske diskurser, vigtigere er det givet at hverdagens tv-seening naturliggør de kulturelle forbindelser, der skaber nationalfølelsen.

\section{Sprog og formater i tv-fiktion}

En af de måder, hvorved tv gør det nationale til en given, konstituerende realitet, er gennem sproget. Forestillinger, der knytter globaliseringen sammen med forestillingen om kulturel homogenitet, overser sprogets betydning for den kulturelle særegenhed og den nationale identitet. Uden at underkende den position engelsk indtager som verdens lingua franca, så er forbindelsen mellem sprog og nation stadig vigtig og i visse tilfælde fundamental for at forstå vores forestillinger om kulturel enhed og forskel. Konstruktionen af national identitet er stadig uadskillelig fra sproget (De Swaan 1991; Edwards 1985). Sproget er grundlaget for de strategier for inklusion og eksklusion, som er centrale for identiteten (Anderson 1983; Hall og du Gay 1996).

Fra dette perspektiv er det vigtigt at overveje forholdet mellem medier og sprog. Sproget sætter de kulturelle grænser, som bestemmer handelen med programmer. Den globale handel med tvprogrammer er formet omkring "geo-linguistiske markeder" (Sinclair, Jacka og Cunningham 1996). I en tid hvor tv-seerne synes at se de samme eller lignende programmer, er det stadig tv-programmer på hverdagssproget, der skaber følelsen af kulturelt tilhør og fungerer som det privilegerede sted for nationernes reproduktion. I en verden gennemsyret af Hollywood-programmer, er det medierede hverdagssprog både kulturelt lim og en påmindelse om, at man tilhører et bestemt kulturelt fællesskab.

Styrken ved tv's sprog (og medieret sprog generelt) ligger i dets usynlighed, i det faktum at vi sjældent bemærker det. Sproget er et eksempel på 'banal nationalisme' (Billig 1995). Billig argumenterer for, at de ideologiske vaner, som gør det muligt for nationer at reproducere sig selv, "ikke er noget, der ligger fjernt fra hverdagen [...] nationen indikeres dagligt eller udtrykkes i borgernes liv" (p 6). For ham er billedet af flaget, der hænger ubemærket på offentlige bygninger, et af de bedste eksempler på banal nationalisme. Sproget kan forstås på samme måde. Den fælles antagelse af, at sprog og nation er "naturligt" uadskillelige, skjuler ifølge Billig det kunstige i sådanne relationer (se også Anderson 1983).

Følger vi Billigs argument, kan vi forstå tv's sprog som et redskab i den daglige reproduktion af nationen. Tv naturliggør båndene mellem sprog og nation. Styrken ved tv's sprog ligger i, at det er almindeligt og konstant væver et usynligt bånd mellem nation og sprog. Tv holder flaget højt for nationalfølelsen, ofte gennem faste programmer på bestemte sprog. Dermed står tv i modsætning til 'mediebegivenheder' (Dayan og Katz 1992), som bevidst appellerer til det nationale gennem fælles medieoplevelser. Mediebegivenheder såsom officielle begravelser, underskrivelsen af internationale aftaler eller globale sportstransmissioner er øjeblikke, hvor kollektivet mobiliseres i nationens navn. $T_{v}$ fungerer her i nationalismens tjeneste - forstået som politisk bevægelse. I modsætning hertil binder tv også de nationale bånd i hverdagen i form af "banal nationalisme". Her er der tale om aktiv påmindelse om den nationale bevidsthed snarere end aktiv mobilisering af samme. Mens dækningen af store begivenheder, som samler ekstraordinært store seerskarer, er sporadisk, holder tv konstant nationen i live ved at "holde flaget højt" for talesproget og ved at trække sproglige grænser, som man fx ser det med "dobbelt-kulturelle" medier, der bevarer nationale identiteter ved at vedligeholde de sproglige bånd i immigrant-kulturer (Sinclair og Cunningham 2000). At der ikke er blevet lagt vægt nok på dette forhold skyldes formodentlig, at tv's sprog er usynligt. Mens litterære studier har fokuseret på, hvordan mediernes fortællinger og fortællemåder har udtrykt det nationale, har historisk-sociologiske studier tematiseret den rolle tv og medieindustrien har haft i skabelsen af forestillede nationale fællesskaber (Schannell og Cardiff 1991; van der Bulck 2001). Det er også nødvendigt at overveje, hvordan medierne spreder og forstærker nationalfølelser ved at vedligeholde 
sproglige bånd. Samtidens tv bidrager, ligesom avisen i det nittende århundrede, til at udbrede nationale kulturer ved at sprede dagligdagssproget og forstærke de sproglige bånd i befolkningen. Således repræsenterer programmer på dagligdagssproget det nationale, også selvom om de ikke eksplicit er optaget af at udtrykke nationalkulturen.

Ved at legitimere et bestemt sprog og udelukke andre gør tv det muligt at genkende sprogbaserede nationale fællesskaber. Behovet for eftersynkronisering af og undertekster på importerede programmer og film viser, at ethvert forsøg på at producere kulturel ensartethed kolliderer med dagligdagssprogets modstandskraft.

Formaternes globale popularitet demonstrerer sprogets modstandskraft som et konstituerende element i nationalidentiteten. Sammenlignet med reality-programmer er fiktion sværere at formattere og tilpasse. Manuskriptbaserede programmer, inklusive fiktion, har en tendens til at være mere kulturelt specifikke og de er dyrere at producere. Bortset fra disse forskelle er fiktionsprogrammer også blevet formatteret af især to grunde: De sproglige barrierer og den kulturelle "viden" som tv-dramaer og komedier forudsætter. Selv når lande har en sproglig og kulturel baggrund, der ligner hinanden meget, som det fx gælder USA og England, rummer programmer betydningsdimensioner, som går tabt, når de krydser grænserne (Miller 2000). Formater gør det muligt at tilpasse ikke kun indholdet af den oprindelige produktion men også sproget.

Latinamerika er en interessant case, når man vil studere dette, fordi skellet mellem det spanske og det portugisiske område bliver ved med at være en af de mest synlige skillelinier i regionens kulturelle geografi på trods af, at den regionale handel med programmer er blevet intensiveret. Adskillelsen er ikke så udtalt som i Europa, hvor medieprojekter, der skal skabe regionale kulturer, løber ind i problemer med sproglig fragmentering og hverdagssprogets styrke (Kilbourn 1993).

Alligevel er problematikken omkring sprogdeling vigtig, særlig når den ses i forhold til den regionale handel med programmer. Seriel fiktion, primært telenovellaer, udgør stadig rygraden af de latinamerikanske programflader. Selvom programfladerne har mange reality-programmer, betragter tv-selskaberne stadig telenovellaerne som den vigtigste genre. Sproget har været det springende punkt $\mathrm{i}$ den regionale handel med telenovellaer. Siden 1970erne har mange brasilianske telenovellaer været vist eftersynkroniseret i de spansk-talende lande (og i Spanien), og nogle er stadig meget populære. I takt med at tv-industrien er modnet, og de statsejede tv-stationer er blevet privatiseret (Waisbord 2000b), er flere spansksprogede produktioner fra forskellige lande blevet tilgængelige på det internationale marked. Dette har dæmpet lysten til at importere brasilianske telenovellaer hos de programansvarlige i de spansktalende lande. Selvom disse generelt har en flottere produktion, gribende historier og ofte rummer spektakulære udendørsoptagelser som har stor appel til seerne, rammer de ind i en kulturbarriere. En hindring er helt sikkert det forhold, at nogle af de mest populære brasilianske telenovellaer er indlejret i nationalt bundne historier, politiske forhold og myter, som ikke kan finde resonansbund hos et globalt publikum. Samtidig arbejder disse kendetegn også til fordel for de brasilianske telenovellaer i dét de "brander" dem som "det eksotiske andet" på de internationale markeder. I mange latinamerikanske lande har den største hindring dog været sproget. Selv ikke den bedste eftersynkronisering kan kompensere for, at de oprindelig er lavet på portugisisk. Denne kulturelle afstand har haft størst betydning i lande, der har en betragtelig hjemlig produktion (som fx Mexico), hvor publikum er vant til programmer på deres eget sprog både på hjemlige produktioner og på eftersynkroniserede Hollywoodproduktioner.

Noget lignende sker på den anden side af sprogkløften. I Brasilien, et land der producerer et stort antal programmer, vises kun et fåtal udenlandske programmer på de hjemlige tv-kanaler. Som en af verdens største mediekorporationer og landets dominerende tv-selskab i årtier har Globo produceret tusindvis af timer. Selskabets årlige produktion blev i 2000 estimeret til 2239 timer (Fernandez 2001). Selskabet producerer $80 \%$ af sine egne programflader (Cajueiro 2000). SBT og Bandeirantes producerer også et betragteligt timetal, særlig varieté- og talkshows. I et forsøg på at tage en bid af Globos seerandel, har begge selskaber forsøgt at importere programmer fra spansktalende lande for at holde omkostningerne nede, særligt da en recession fik reklameindtægterne til at falde. På grund af den sprogforskel som portugisisk eftersynkronisering ikke helt kan kompensere for, indkøbte man formater fra populære telenovellaer. SBT har købt formater til telenovellaer fra Televisa, som så er 
blevet produceret i Brasilien med lokale skuespillere. Bandeirantes købte den populære telenovella Chiquititas rettet mod unge af det argentinske Telefe. Telefe overvågede produktionen af en portugisisk version med brasilianske skuespillere, som blev indspillet i Buenos-Airos. Globo, der ikke købte programmer fra spansktalende latinamerikanske lande i årtier, købte manuskriptet til det colombianske hit "Betty la Fea" for $\$ 100.000$, et behersket beløb i lyset af at prisen for en times produktion af selskabets storslåede telenovellaer er flere gange så høj. Globo retfærdiggjorde beslutningen ved at fastslå, at man ville producere en version, der var tilpasset brasiliansk kultur og tv. Men flere kommentatorer lagde vægt på at Globos beslutning var motiveret af en helt anden interesse - nemlig at forhindre SBT og Bandeirantes, som har en lang tradition for at importere succesfulde spansksprogede telenovellaer, fra at få fingre i de brasilianske rettigheder til et potentielt hit.

Men de lingvistiske barrierer er ikke begrænset til forskelle i sprog. Mangfoldigheden af spanske accenter er endnu en kulturel barriere for handelen med tv-programmer i området. Man kunne hævde, at accenter - ikke kun spansk - er blevet synlige markører af national identitet i det spansktalende Latinamerika. Som Nancy Morris (1999, 55) skriver, så er "accenter... måske en af de mest effektive måder at etablere lokal identitet på".

Man kunne sige, at Latinamerika er et område, som er adskilt af det samme sprog. Det spanske imperium påtvang kulturel ensartethed ved hjælp af sproget, og derfor blev sproget ikke det distinktive for de nationale identiteter, der skulle udvikles efter kolonitiden, som det gjorde i andre postkoloniale samfund (se Mar-Molinero 2000). Fordi de fleste stater i Latinamerika (bortset fra Brasilien og de engelsk-, hollandsk- og fransktalende Caribiske øer) havde samme sprog, kunne de ikke defineres som nationer med udgangspunkt i sproget. Kun i få lande blev oprindelige sprog accepteret fra officiel side som en del af det nationale fællesgods (fx Guarani i Paraguay), men disse sprog havde begrænset, hvis nogen, adgang til de nationale medier. Uden forståelse for den sproglige diversitet i de latinamerikanske lande bidrog radio, film og tv i stor stil til at gøre bestemte accenter til distinktive markører for det nationale. De gjorde ikke blot spansk til nationalsprog, særligt i den uuddannede del af befolkningen som er spredt ud over enorme og svært fremkommelige områder, men de natio- naliserede også hovedstædernes accenter (MartinBarbero 1993).

På det regionale niveau var tv ansvarlig for udbredelsen af mexicanske accenter. Dette var der to årsager til. For det første har de latinamerikanske seere set film- og tv-produktioner fra Hollywood i årtier, og disse er altovervejende blevet synkroniseret på mexicanske accenter. For det andet har Televisa eksporteret telenovellaer og børne-tv programmer til hele området fra starten af 1970erne, og nogle af disse har været enormt populære. Resultatet har været, at mexicansk er blevet fællessprog på latinamerikansk tv og opfattes som mere "neutralt" end andre spanske accenter. Dette har givet Televisa enorme konkurrence-fordele i forhold til tv-producenter fra andre lande. Televisas succes er baseret på den kendsgerning, at seerne er fortrolige med den mexicanske accent, en fortrolighed som deres produktioner forstærker. Denne fordel er ikke begrænset til Sydamerika men strækker sig også ind i USA i kraft af Televisas mangeårige status som førende programleverandør til det spansktalende tv-marked. Udover det kulturelle nød Televisa også økonomiske fordele; firmaet udvidede tidligere i regionen end andre tv-industrier og producerede et substantielt antal tv-timer.

Fordispansktalende seere generelt ervant til mexicanske accenter, lyder accenter fra andre områder "fremmede". Dette er brasilianske producenter helt bevidste om, og de foretrækker også at eftersynkronisere de produktioner, der er rettet mod det latinamerikanske marked på mexicanske accenter. Det har også været den største hindring for at andre latinamerikanske producenter har kunnet komme ind på markedet. Udover forretningsmæssige hindringer er de også stødt mod den kulturelle mur, som accenterne udgør. For argentinske programmer er accenter $\mathrm{fx}$ den primære kulturelle hæmsko for eksport til Equador. Situationen er anderledes på sydspidsen samt i Bolivia og Peru, hvor seerne er mere fortrolige med argentinske accenter, særligt efter at man begyndte at sende via satellit fra Telefe og andre kabel-netværk baseret i Buenos-Airos i starten af 1990erne. Andre steder afviser seerne de argentinske dialekter, særligt i lande hvor man har set mexicanske programmer i årtier, fordi man har manglet indenlandsk fiktion (som det fx har gjort sig gældende i Mellemamerika).

Efter primært at have været udsat for nationale accenter opfatter mexicanske seere andre accenter som fremmede. Udstyret med en enorm produk- 
tionskapacitet og kæmpe videoteker, har Televisa vænnet de hjemlige seere til mexicanske accenter. Og den begrænsede mængde udenlandske programmer er overvejende Hollywoodproduktioner, primært film (Sanchez-Ruiz 2000). I et forsøg på at mindske Televisas seerandel, tyede det nystartede TV Azteca til egenproduktioner og uafhængige produktioner og i visse tilfælde til regionale shows. Men i erkendelse af problemet med at overvinde sprogbarrieren, endte de med at producere versioneringer af populære programmer fra regionen, som $\mathrm{fx}$ det argentinske Chiquititas.

Accentbarrieren er også tydelig i handelen med programmer mellem Spanien og Latinamerika. Tvseerne er ikke vant til hinandens accenter. Kun en lille del af de spanske produktioner har været vist på Latinamerikansk tv. Spanske seere har vænnet sig til den hjemlige accent i både nationale og udenlandske programmer. Når man endelig købte ind i Latinamerika var det ofte manuskripter eller formater - og ikke originale programmer. I de senere år har man fx købt formater til argentinske programmer (underholdningsshows, quizzer og drama-produktioner) og produceret hjemlige versioner som inkorporerer lokale nyheder, referencer og figurer.

\section{Globalisér, McDonaldisér}

Trafikken med tv-formater i de spansk og portugisisk talende lande antyder, at formater tillader tv-selskaberne at overvinde sproglige barrierer. Det har Hollywoodselskaberne lært i den senere tid: Fordi tv-seerne foretrækker programmer på deres eget "sprog" (og indenlandske produktioner), er det ikke nok bare at dumpe prisen på programmer for at erobre verdensmarkedet. Den tid er forbi, hvor stigende efterspørgsel efter programmer fik tv-selskaberne til at powershoppe Hollywoodproduktioner. Og det gælder særligt på de største og mest velhavende markeder. I en verden med sproglig diversitet og mere modne tv-industrier, har Hollywoods tv-studier måttet finde på nye og kreative måder at tjene penge på. Samproduktioner med indenlandske selskaber om programmer på lokale sprog og andre typer partnerskab illustrerer den "tænk globalt, lav programmer lokalt" filosofi, som for tiden dominerer tv-industrien. Format-tv er et eksempel på "glokalisering" - resultatet af en "multikulturel" forretningsstrategi som tager hensyn til kulturel forskellighed. Dette hensyn skyldes ikke respekt for eller interesse i at bevare en multikulturel verden men ønsket om at maksimere profitten. For globale tv-selskaber er kulturel forskel ikke en hindring, men, hvis den medtænkes på den rigtige måde, kan den være en gevinst. Programhybrider giver mening, fordi de giver overskud. I den internationale arbejdsdeling af kulturarbejde er de lokale selskaber mere opmærksomme på den lokale sensibilitet, end de globale selskaber er, og derfor er de bedre til at udvikle programmer, som kan indarbejde både det lokale og det nationale. I trafikken med verdensomspændende tv-brands skal samarbejdet mellem globale og lokale selskaber imødekomme den kulturelle diversitet som en komponent på det internationale marked. Kulturel forskel er et forretningsspørgsmål og ikke et politisk projekt.

I forsøget på at håndtere en virkelighed, der omfatter en global økonomi og lokale kulturer, er formater blevet et brugbart redskab til at overvinde kulturelle grænser, som samtidig gør det muligt at drage økonomisk fordel af de grundlæggende forandringer, som de forskellige tv-industrier har gennemgået de seneste årtier. Formater er en slags McTv. Som et stenografisk udtryk for McDonalds fast food-kæde, står Mc for en forretningsmodel kendetegnet ved effektivitet, kalkulerbarhed, forudsigelighed og kontrol, som tilpasser produkter til lokale behov, ofte med udgangspunkt i kulturelle faktorer (Ritzer 1998). Overført til tv-industrien repræsenterer formater den globale kommercialisering af et effektivt og forudsigeligt program, som kan bøjes i forhold til den lokale smag. McTv handler om at sælge duelige programideer, der er så fleksible, at de kan tilpasses lokale kulturer. Formaternes nationale oprindelse er ikke så vigtig som deres effektivitet.

Formater er "af-territorialiserede" (se Tomlinson 1999); de har ikke noget hjemland, de repræsenterer den afkobling af kultur, geografi og socialt rum, der kendetegner globaliseringen. Tegn på kulturelt territorium er fjernet, så lokale producenter kan give formatet lokalt præg og lokale seere paradoksalt kan føle sig hjemme, når de ser programmet.

Lokalpræget skal udslettes, så det kan genskabes i den udstrækning, det ikke ændrer det grundlæggende koncept. Selvom alle tv-selskaber kan skabe sådanne formater og markedsføre dem globalt, er det Hollywood og nogle europæiske tv-selskaber, der har de største fordele på dette marked. Formaternes popularitet antyder, at den globale tv-industri er i gang med at udvikle sig til en enorm kulturel 
støvsuger, som suger ideer til sig fra hele verden og gør dem til varer. I en globaliseret verden møder pengestrømme mindre modstand, når de skal krydse grænserne, men tv-programmer løber fortsat ind i kulturelle og sproglige barrierer. Økonomiske og kulturelle barrierer opløses ikke lige let.

\section{Hvor det globale møder det lokale}

Tv-industriens udvikling kan bidrage til forståelsen af handelen med tv-programmer. Siden 1960erne har analyser af dette emne afspejlet ikke bare den politiske og teoretiske debat men også den internationale tv-handels tilstand. Teorier om medieimperialisme og "kulturel ensretning" prægede den første fase i 1960erne og 1970erne, der var domineret af Hollywoodproduktioner til verdens spæde tv-industrier. I 1980erne og 1990erne fremstod en ny fase, hvor man så en række nye producenter og eksportører, især i tredje verdens landene, vinde en position på markedet. Her omkring årtusindskiftet ser vi igen en ny fase kendetegnet ved, at flowet af programmer og kapital bliver mere komplekst - og vi ser nye udviklinger i tv's økonomi, produktion og eksport.

En af de nye ting er, at formater appellerer så meget til eksportører og købere. Tidens handel med formater viser, at globaliseringen af mediernes økonomi og kultur hænger sammen men ikke er identiske. Globaliseringen er ansvarlig for de store ændringer i tv-systemernes struktur. Privatisering og deregulering har åbnet dørene for, at kapital og teknologi kan flyde bevæge sig over grænserne. Disse forandringer har givet tvbranchen nye muligheder for at bevæge sig ind på internationale markeder gennem samarbejdsaftaler, programsalg og produktionsaftaler mv. Globaliseringen har destabiliseret den forbindelse, der tidligere var mellem stat og kapital, geografi og handel, det lokale og det globale. Konflikter kan ikke længere reduceres til modsætningen mellem "det nationale og det fremmede". Der er opstået en mangfoldighed af alliancer og konflikter. Regeringer og lokale selskaber har prøvet at imødegå udenlandske konglomerater ved at kræve, at ejere af medievirksomhed skal have statsborgerskab og ved at begrænse den procentdel som udenlandske selskaber kan eje af indenlandske virksomheder (Morris og Waisbord 2001). Sådanne forsøg på at begrænse den globale kapitalstrøm omgås af inter- nationale og nationale selskaber, der har erkendt deres fælles behov og derfor indgår samarbejde.

På baggrund af disse udviklinger er industrien generelt blevet mere integreret. TV-systemernes struktur er blevet strømlinet i den private models ånd. Uanset hvor selskabets hovedkvarter ligger, er mantraet forretning. I takt med at forskellige lokale industrier er modnet, er et nyt kuld producenter begyndt at sælge programmer på verdensmarkedet. Dette har øget markedets kompleksitet. Tv-økonomiens globalisering har ikke gjort de nationale kulturer irrelevante. Selv når skærmen har været spækket med Hollywood-varer, er tv stadig et af de vigtigste steder for artikulationen af det nationale. Mediefortællinger og sprog skaber et kulturelt tilhørsforhold.

Disse spørgsmål må undersøges ved at udvide overvejelserne over globaliseringens konsekvenser til tv-industrien. Effekten af det internationale tv-flow skal ikke kun berøre området for "effekt/ seer-aktivitet" men skal også ses i lyset af de tabte muligheder for kulturel mangfoldighed. Reality-show-formatets popularitet som et billigt programalternativ tilsidesætter uden tvivl genrer som drama og komedie, der tilbyder andre muligheder for at udtrykke nationalfølelser. Når bundlinien styrer og reality-formater kan købes for en brøkdel af det et fiktionsprogram koster, producerer kommercielle tv-selskaber ikke fiktion (Alvarado 2000). Format-tv udsletter ikke de nationale kulturer, men som et udtryk for en global industri, der udelukkende tænker i hurtig kommerciel succes og ikke har tålmodighed nok til nyskabelse, bliver tv's repræsentation af lokale og nationale fællesskaber mindre varierede og komplekse (Waisbord 1998).

\section{Litteratur}

Allen, Robe 1995. To be continued: Soap operas around the world. London: Routledge.

Alvarado, Manuel. 2000. The "value" of TV drama: Why bother to produce it? Television \& New Media 1 (3): 30719.

Anderson, Benedict 1983. Imagined communities: Reflections on the origins of nationalism. London: Verso.

Andrews, Edward L. 2000. Europe's "reality" TV: Chains and Big Brother. The New York Times, April 11.

Billig, Michael. 1995. Banal Nationalism. London: Sage.

Biltereyst, Daniel, and Philippe Meers. 2000. The international telenovela debate and the contra-flow argument: A reappraisal. Media, Culture and Society 22 (4): 393-413.

Cajueiro, Marcelo. 2000. "If it ain't broke," Variety, April 3. 
Carter, Bill. 2000. At TV Bazaar, US companies look to buy, not just sell. The New Tork Times, October 9.

Craves, Richard. 2000. Creative industries: Contracts between art and commerce. Cambridge, MA: Harvard University Press.

Dayan, Daniel, and Elihu Katz. 1992. Media events: The live broadcasting of history. Cambridge, MA: Harvard University Press.

De Swaan, Abram. 1991. Notes on the merging global language system: Regional, national, and supranational. Media, Culture and Society 13:309-23.

Edwards, John. 1985. Language, society and identity. Oxford: Blackwell.

Fernandez, Angel. 2001. El boom de la telenovela. El Mundo (Spain). http://www.elmundo.es/2001/02/22/ television/957968.html.

Fiske, John. 1990. Women and quiz shows: Consumerism, patriarchy, and resisting pleasures. In Television and women's culture: The politics of the popular, edited by Mary Ellen Brown. London: Sage.

Fry, Andy. 2000. Europe secure as leader of reality programming. Variety, September 25, M4-M8.

Gitlin, Todd. 1983. Inside prime time. New York: Pantheon.

Golding, Peter. 1998. Global village or cultural pillage? The Unequal inheritance of the communications revolution. In Capitalism and the information age, edited by Robert W. McChesney, Ellen Meiksins Wood, and John Bellamy Foster. New York: Monthly Review Press.

Grantham, Bill. 2000. "Some big bourgeois brothel"; Contexts for France's cultural wars with Hollywood. Bedfordshire, UK: University of Luton Press.

Guider, Elizabeth. 2000. Two-way transatlantic. Variety, September 25, M1-M2.

Hall, Stuart, and Paul du Gay. 1996. Questions of cultural identity. London: Sage.

Hils, Miriam. 1998. MTV sings in locallingos. Variety, August 10, p. 24.

Hoskins, Colin, Stuart McFayden, and Adam Finn. 1997. Global television and film. Oxford: Oxford University Press.

Hughes, Janice. 2001. Rewriting the traditional broadcast revenue model. Financial Times (London), June 19, p. 2.

Jensen, Elizabeth. 2000. The changing face of international TV. Los Angeles Times, October 27, Fl.

Kilborn, Richard. 1993. "Speak my language": Current attitudes to television subtitling and dubbing. Media, Culture \& Society 15:641-60.

Koranteng, Juliana. 1999. TV goes local: Pan-regional networks launching local channels. Advertising Age 70 (2): 32-3.

Langdale, John V. 1997. East Asian broadcasting industries: Global, regional, and national perspectives. Economic Geography 73:305-21.

Mar-Molinero, Clare. 2000. The politics of language in the Spanish-speaking world. London: Routledge.

Martin-Barbero, Jesus. 1993. Communication, culture and hegemony: From the media to mediations. London: Sage.

Miller, Jeffrey S. 2000. Something completely different: British television and American culture. Minneapolis: University of Minnesota Press.
Miller, Toby, Nitlin Govil, John MeMurria, and Richard Maxwell. 2001. Global Hollywood. London: BFI.

Moran, Albert. 1998. Copycat TV: Globalization, program formats, and cultural identity. Luton, UK: University of Luton Press.

Morris, Nancy. 1999. US voices in UK radio. European fournal of Communication 14 (1): 37-59.

Morris, Nancy, and Silvio Waisbord, eds. 2001. Media and globalization: Why the state matters. Lanham, MD: Rowan \& Littlefield.

Moyes, Jojo. 2000. TV imperialism goes into reverse as British shows invade the US. The Independent (London), August 4.

Olson, S.R. 1999. Hollywood planet. Mahwah, NJ: LEA.

O'Regan, Tom. 2000. The international circulation of British television. In British television: $A$ reader, edited by Edward Buscombe, 303-22. Oxford: Oxford University Press.

Otnes, Cele. 1996. A critique of daytime television game shows and the celebration of merchandise: The Price is Right. Fournal of American Culture 19 (3): 51.

Pursell, Chris. 2001. To import or to format? That is the question. Electronic Media, January 15, 64.

Ritzer, George. 1998. The McDonaldization thesis: Explorations and extensions. London: Sage.

Robertson, Roland. 1992. Globalization: Social theory and global culture. London: Sage

Sanchez-Ruiz, Enrique. 2000. Globalization y convergencia: Retos para las industrias culturales Latinoamericanas. Typescript.

Scannell, Paddy, and David Cardiff. 1991. A Social History of British Broadcasting: Serving the Nation, 1923-1939. Oxford: Blackwell.

Schneider, Michael. 2000. Whiz quiz hits global jackpot. Variety, July 17.

Segrave, Kerry. 1998. American television abroad: Hollywood's attempt to dominate world television. Jefferson, NC: McFarland.

Sinclair, John. 1999. Latin American television: A global view. Oxford: Oxford University Press.

Sinclair, John, and Stuart Cunningham. 2000. Go with the flow: Diasporas and the media. Television \& New Media 1 (1): 11-31.

Sinclair, John, Elizabeth Jacka, and Stuart Cunningham, eds. 1996. New patterns in global television: Peripheral visions. Oxford: Oxford University Press.

Skovmand, Michael. 1992. Barbarous TV international. In Media cultures: Reappraising transnational media, edited by Michael Skovmand and Kim Christian Schrøder, 84-103. London: Routledge.

Straubhaar, Joseph. 1991. Beyond media imperialism: Asymmetrical interdependence and cultural proximity. Critical Studies in Mass Communication 8:39-59.

Tomlinson, John. 1999. Globalization and culture. Chicago: University of Chicago Press.

Trinta, Aluizio R. 1998. News from home: A study of realism and melodrama in Brazilian telenovelas. In The television studies book, edited by Christine Gerghty and David Lusted, 275-86. London: Arnold.

Tunstall, Jeremy, and David Machin. 1999. The Anglo-American media connection. Oxford: Oxford University Press. 
van der Bulck, Hilde. 2001. Public service television and national identity as a project of modernity: The example of Flemish television. Media, Culture and Society 23:53-69.

Waisbord, Silvio. 1998. The ties that still bind: Media and national cultures in Latin America. Canadian Fournal of Communication 23:381-411.

Waisbord, Silvio. 2000a. Industria global, cultural y politica locales: La internacionalizacion de la television Latinoamericana. America Latina Roy (Salamanca) 20 (August): 77-85.

Waisbord, Silvio. 2000b. Media in Latin America: Between the rock of the state and the hard place of the market.
In De-Westernizing media studies, edited by James Curran and Myung-Jin Park. London: Routledge.

Waterman, David, and Everett M. Rogers. 1994. The economics of television program production and trade in Far East Asia. Fournal of Communication 44 (3): 89-111.

Weinraub, Bernard. 2000. Sudden explosion of game shows threatens the old TV staples. The New York Times, February 9, El, E3.

Whannel, Gary. 1993. Fields in vision. Television sport and cultural transformation. London: Routledge.

Silvio Waisbord er Assistant Professor ved Rutger's University, New Jersey. 